\title{
Landform and surface attributes for prediction of rodent burrows in the Western Usambara Mountains, Tanzania
}

JOEL L. MELIYO ${ }^{1}$, BONIFACE H.J. MASSAWE ${ }^{1}$, BALTHAZAR M. MSANYA ${ }^{1 *}$, DIDAS N. KIMARO ${ }^{2}$, PROCHES HIERONIMO ${ }^{2}$, LOTH S. MULUNGU ${ }^{3}$, NGANGA I. KIHUPI ${ }^{2}$, JOZEF A. DECKERS ${ }^{4}$, HUBERT GULINCK ${ }^{4}$ and HERWIG LEIRS 5

${ }^{1}$ Department of Soil Science, Sokoine University of Agriculture, P.O. Box 3008, Morogoro, Tanzania

${ }^{2}$ Department of Agricultural Engineering and Land Planning, Sokoine University of Agriculture, Morogoro, Tanzania

${ }_{3}^{3}$ Pest Management Centre, Sokoine University of Agriculture, P.O. Box 3110, Morogoro, Tanzania

${ }^{4}$ Department of Earth and Environmental Sciences, University of Leuven, Celestijnenlaan 200E, Leuven, Belgium

${ }^{5}$ Evolutionary Ecology Group, Universiteit Antwerpen, Groenenborgerlaan 171, B-2020 Antwerpen, Belgium

\begin{abstract}
Previous studies suggest that rodent burrows, a proxy for rodent population are important for predicting plague risk areas. However, studies that link landform, surface attributes and rodent burrows in the Western Usambara Mountains in Tanzania are scanty. Therefore, this study was conducted in plague endemic area of the Western Usambara Mountains in northern, Tanzania, to explore the relationship between rodent burrows, and landform and surface attributes. The study was carried out in three areas corresponding to high (Lokome), medium (Lukozi) and low (Mwangoi) frequency of reported plague cases. Data were collected from 117, 200 and 170 observation sites for Lokome, Lukozi and Mwangoi, respectively using $100 \mathrm{~m}$ x $200 \mathrm{~m}$ quadrats. Remote sensing and field surveys were used to collect data on landform and surface attributes. Rodent burrows were surveyed and quantified by counting the number of burrows in $20 \mathrm{~m} \times 20 \mathrm{~m}$ grids demarcated on the main $100 \mathrm{~m} \times 200 \mathrm{~m}$ quadrats. The collected data were analysed in R software using boosted regression trees (BRT) technique. Rodent burrows were found at an elevation of above $1600 \mathrm{~m}$ in the high and medium plague frequency landscapes. No burrows were found in the low plague frequency landscape situated below 1500m. BRT analysis shows a significant relationship between landform characteristics and rodent burrows in both high and medium plague frequency landscapes. Overall, elevation and hillshade are the most important determinants of rodent burrow distribution in the studied landscapes. It is concluded that in high altitudes, specific landform attributes (hill-shade, slope, elevation) and vegetation cover-favour rodent burrowing.
\end{abstract}

Keywords: landform, plague, rodent burrows, surface attributes, Tanzania

\section{Introduction}

Most studies which were carried out to explain the occurrence and incidence of plague have focused on the influence of climatic factors on the disease vectors (Mills et al., 2010), on vegetation and small mammals (Ralaizafisoloarivony, 2010; MacMillan et al., 2011), on biological factors particularly flea diversity and plague persistence (Amatre et al., 2009; Eisen et al., 2012), on land use trajectories (Annaert, 2010) and on human activity flows and community behaviour (Hubeau, 2010). Few studies are available regarding environmental and behavioural risk factors associated with plague infection. Studies in Lushoto District, Tanzania, indicate that ecological factors comprising landform (elevation) and rainfall have influence on rodent population and fleas which are linked to plague outbreaks (Kilonzo et al., 1997; Kamugisha et al., 2007).

Studies carried out by Neerinckx et al. (2010) in the Western Usambara Mountains, Tanzania, at regional scale demonstrate that there is a high correlation between plague reported cases and elevation. Similar observations were made by MacMillan et al. (2011; 2012) in the West Nile Region of Uganda. In this study, logistic regression shows that altitude alone could predict $73 \%$ of households with plague infection. In another study in the Western Usambara Mountains, Tanzania, it was observed that hamlets located in/or near valley bottoms have higher

* Correspondence: Balthazar M. Msanya; E-mail: bmmsanya@gmail.com 
probabilities of being plague-positive than those far away (Neerinckx et al., 2010). It was suggested that certain fine scale environmental variables could help predict plague risk areas. However, such fine scale data are mostly lacking.

There is a rich literature on the survey of rodent burrows and the way they relate to landforms and surface attributes (Reichman \& Smith, 1990; Goyal \& Ghosh, 1993; Randall, 1993; Laundre \& Reynolds, 1993; Davidson et al., 2008; Mora et al., 2010; Naderi et al., 2011). Most of these works have focused on rodents' survival and soil suitability for burrowing. But rodent burrows are in the first place for nursing young rodents, so they are certainly indicative of rodent populations, and may also be a good proxy for the prediction of plague risk areas (Reichman \& Smith, 1990; Randall, 1993; White et al., 2008). In the current study, landform characteristics and surface attributes of agricultural landscapes were investigated to test their importance on the presence of rodent burrows, these being a proxy of rodent population and so also an indicator of the abundance of plague hosts.

\section{Materials and Methods}

\section{Study area}

The study area is located in the Western Usambara Mountains, in Lushoto District, Tanzania (Figure 1). Three sample areas were selected based on diversity of landforms, climatic conditions and historical plague frequencies. The area is located between Universal Transverse Mercator (UTM) coordinates 9474965 through $9502586 \mathrm{~N}$, and 444532 through $472276 \mathrm{E}$ zone 37M. Three sample areas (Lokome, Lukozi and Mwangoi) were selected representing historical high, medium and low plague frequency, respectively. The second criterion was differences in farming systems, climatic variability and the landform.

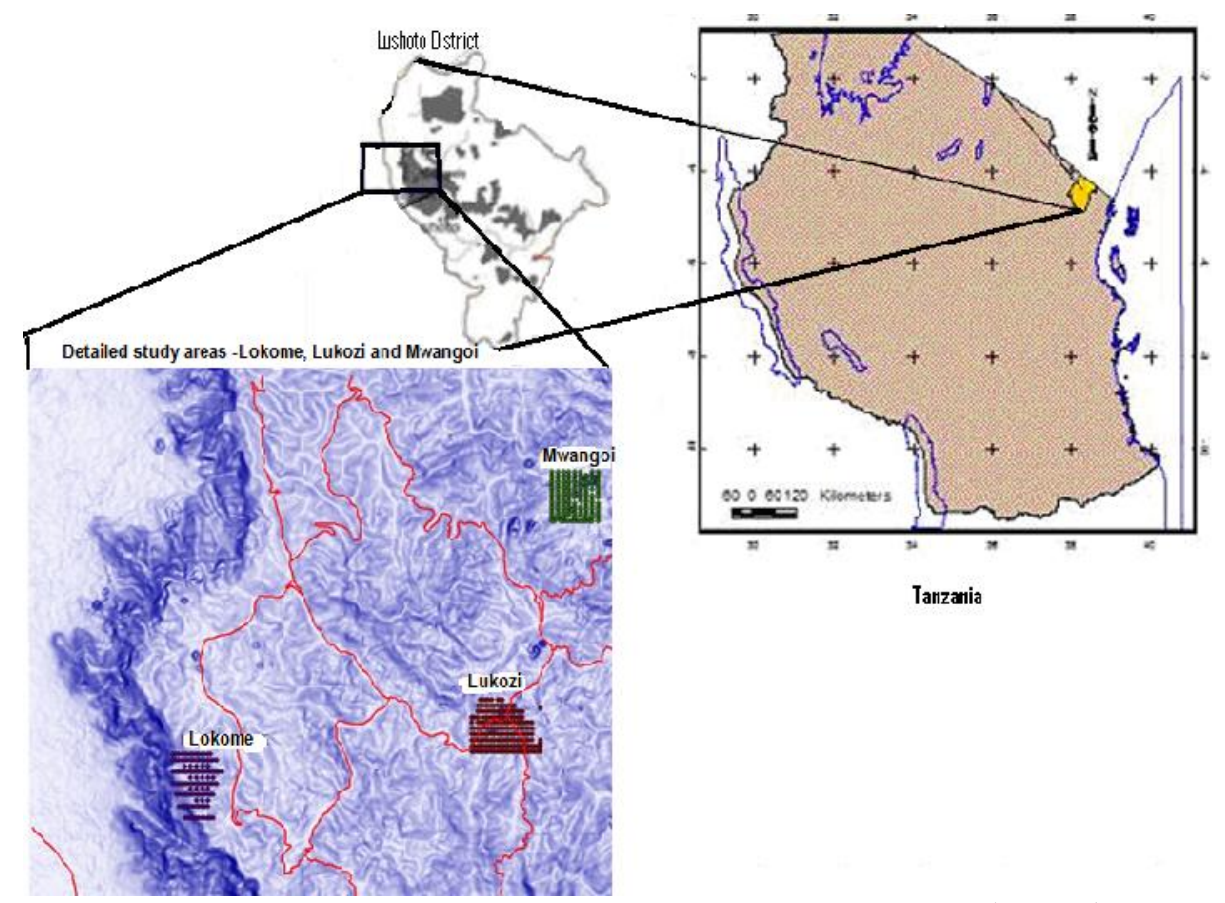

Figure 1: Location map of the study area with landscapes of high (Shume), medium (Lukozi) and low (Mwangoi) plague frequency

The area receives rainfall in two seasons with annual rainfall varying from 500 to $1200 \mathrm{~mm}$ in the high plague frequency; 600 to $1200 \mathrm{~mm}$ in the medium plague frequency and less than 500 to 
$800 \mathrm{~mm}$ per annum in the low plague frequency area. Most of the rainfall in Mwangoi is received during the short rains whereas in Shume and Lukozi areas, it is received during the long rain season. Average annual temperatures are variable and increase from $19^{\circ} \mathrm{C}$ at Shume-Gologolo area over Lukozi, to Mwangoi with $21^{\circ} \mathrm{C}$.

\section{Determination of landform and surfaces characteristics}

Analysis of ASTER DEM was done using ArcGIS 9.3 to calculate continuous surfaces for elevation, (slope gradient (degrees), slope aspect (radians), slope length $(\mathrm{m})$, slope types (straight, convexity and concavity), flow accumulation, flow direction, topographic compound index ( $\mathrm{TCl}$ ), and stream power index (SPI). These were used to extract point values at each data collection site for modelling. Surface characteristics including rock outcrops (\%), surface stones (\%), surface gravels (\%), sealing (yes/no), erosion status (types) and degree, and vegetation cover $\left(\mathrm{m}^{2}\right)$ were determined and quantified according to FAO Guidelines for Soil Profile Description (FAO, 2006).

\section{Rodent burrows}

Grids of 100m down the slope and 200m across the slope were used to identify and study rodent burrows. The sampling design was chosen in order to capture sufficient variation of landform and surface characteristics. In order to capture maximum number of rodent burrows within a grid with minimal errors and bias, smaller grids of $20 \mathrm{~m} \times 20 \mathrm{~m}$ were located within the $100 \mathrm{~m} \times 200 \mathrm{~m}$ for scanning and counting rodent burrows. Data collected included number of rodent burrows, the used and non-used burrows, the burrows' portal orientation (down/up, perpendicular) and burrows' aspect which was determined by a compass direction in degrees and presence or absence of the above ground nests. Other data sets collected on burrows were signs of food presence (yes/no) and droppings (yes/no) which were used to establish whether burrow was actively used or abandoned.

\section{Data analysis}

Although the study involved three areas (Lokome, Lukozi and Mwangoi), the low plague frequency area (Mwangoi) was not included in the 'Boosted Regression Trees (BRT) regression analysis process because it had no burrow data. However, the site was considered in other analyses such as landform analysis e.g. slope curvature, slope gradient and cross-section of the study area. Field data were prepared in MS-Excel 2010 and an attribute table with 317 observation points was linked to geographical information system (GIS). Number of rodent burrows, portal and burrow aspect were dependent variables while 26 landform and surface attributes were the independent variables.

The identification and the rating of landform and surface attributes influencing rodent burrowing in specific locations was done separately for the high and medium plague frequency landscapes using boosted regression trees (BRT) as described by Elith et al. (2008) after adjusting "bag fraction", "learning rate" and "tree complexity" to fit this study. The BRT script (Elith et al., 2008) was run in R version i386 3.0.0., applying the package "gbm" library (Ridgeway, 2007). The BRT parameters used were learning rate $=0.005$ and 0.0005 for high and medium plague frequency landscapes, respectively. The tree complexity and bag fraction used was 5 and 0.5 , respectively. The dataset in this case was set such that the respondent variable was binary $(0,1)$ showing either presence or absence of burrows. Cross-validation by 10 -fold process inbuilt in the BRT was used to assess the model performance. In the 10-fold cross-validation, the data are divided into 10 subsets of equal size. The regression techniques are then applied 10-times each time leaving out one of the subsets and using that subset to complete the prediction (Elith et al., 2008). 


\section{Ethical considerations}

This study received approval from Directorate of Research and Post-Graduate Studies of Sokoine University of Agriculture, Tanzania and Flemish Inter-University Council (VLIR-UOS) of Belgium.

\section{Results}

\section{Variations in landform characteristics among the studied plague frequency landscapes}

Figures 2 to 4 present elevation, slope and slope characteristics variation among the studied plague frequency landscapes. Figure 2 shows topographic cross-section (ABC) indicating elevation heterogeneity in the study area. In the high plague frequency area, the elevation range is from 1,650 to $2,040 \mathrm{~m}$ while in the medium plague frequency area it is from 1,750 to $1,900 \mathrm{~m}$ and it is below $1,500 \mathrm{~m}$ in the low plague frequency area.

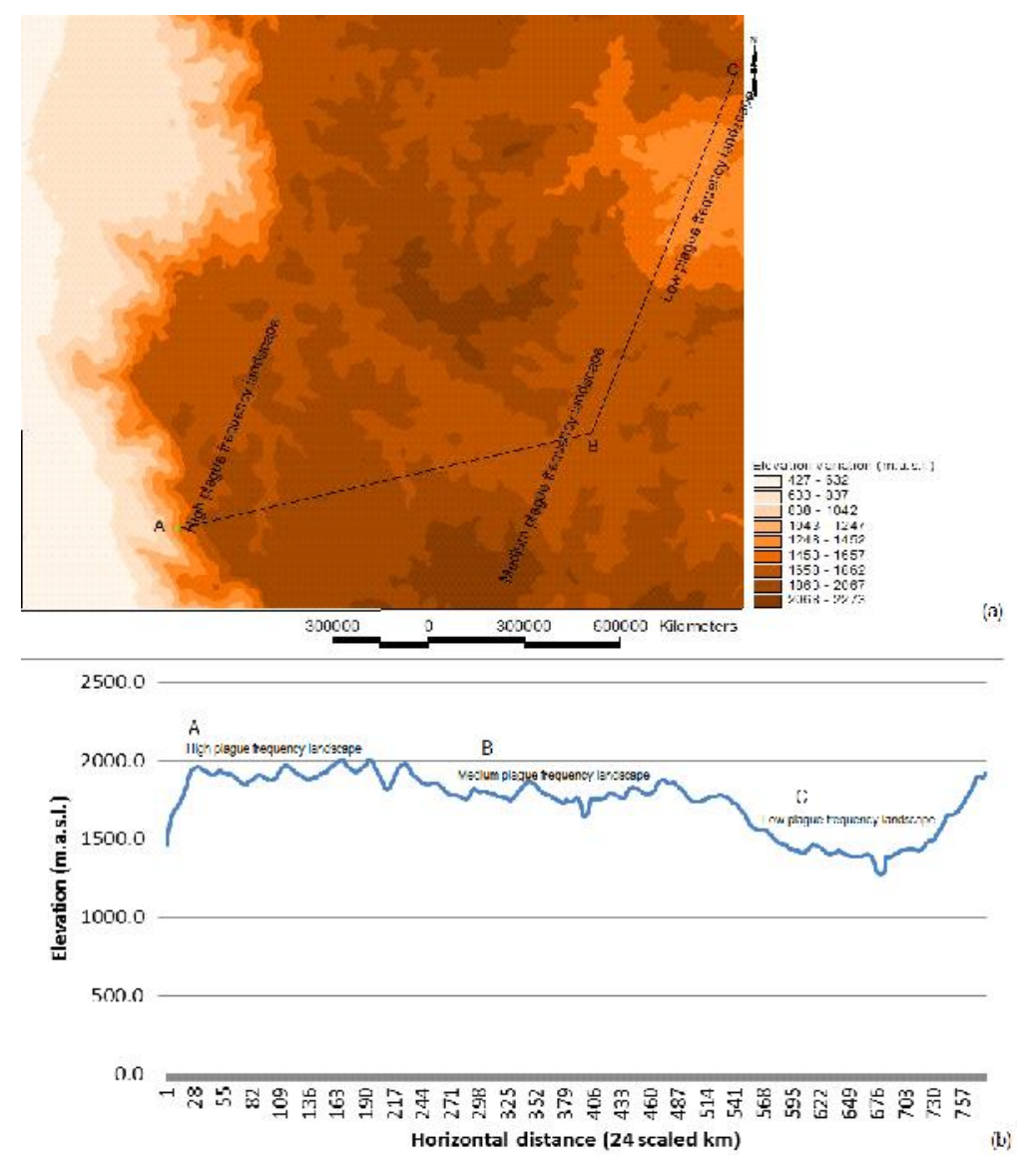

Figure 2: Variation in elevation and slopes in the studied landscapes

Figure 3 shows the mean variation in elevation and slope gradient among the three landscapes: high (Lokome), medium (Lukozi) and low (Mwangoi) plague frequency areas. Results show that there was a significant difference $(p=0.05)$ between the high and low plague frequency areas ( 3 ). Also, there was a statistically significant difference between slopes of high, medium and low plague frequency areas but not between medium and low plague frequency areas. 


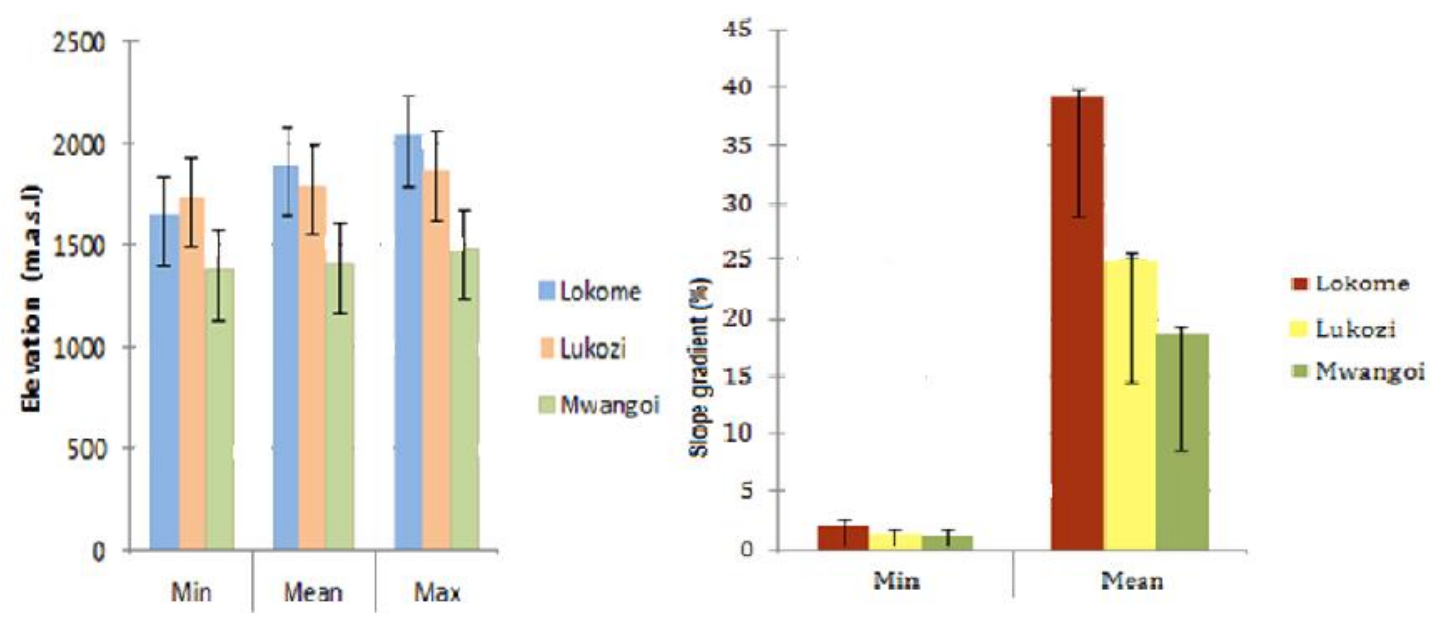

Figure 3: Elevation and slope variation in the studied landscapes

Figure 4 presents slope gradient and slope characteristics (aspect, cross-section and general curvature), indicating the heterogeneity of the study area in terms of landform genesis. Slope gradient ranging from o to 69.8 degrees appears to be the strongest topographic attribute.
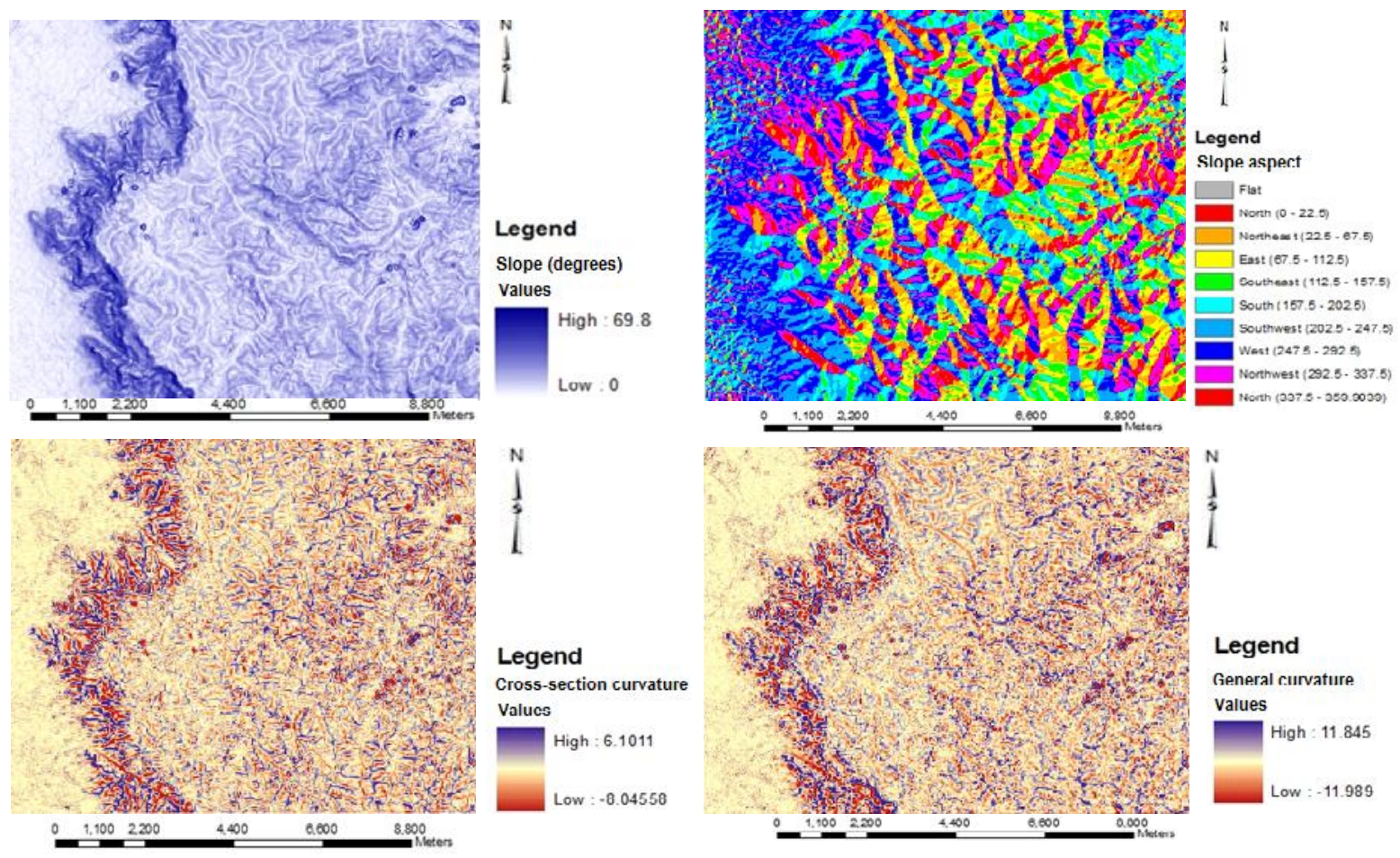

Figure4: Slope characteristics showing the heterogeneity of the study area in terms of landform genesis 


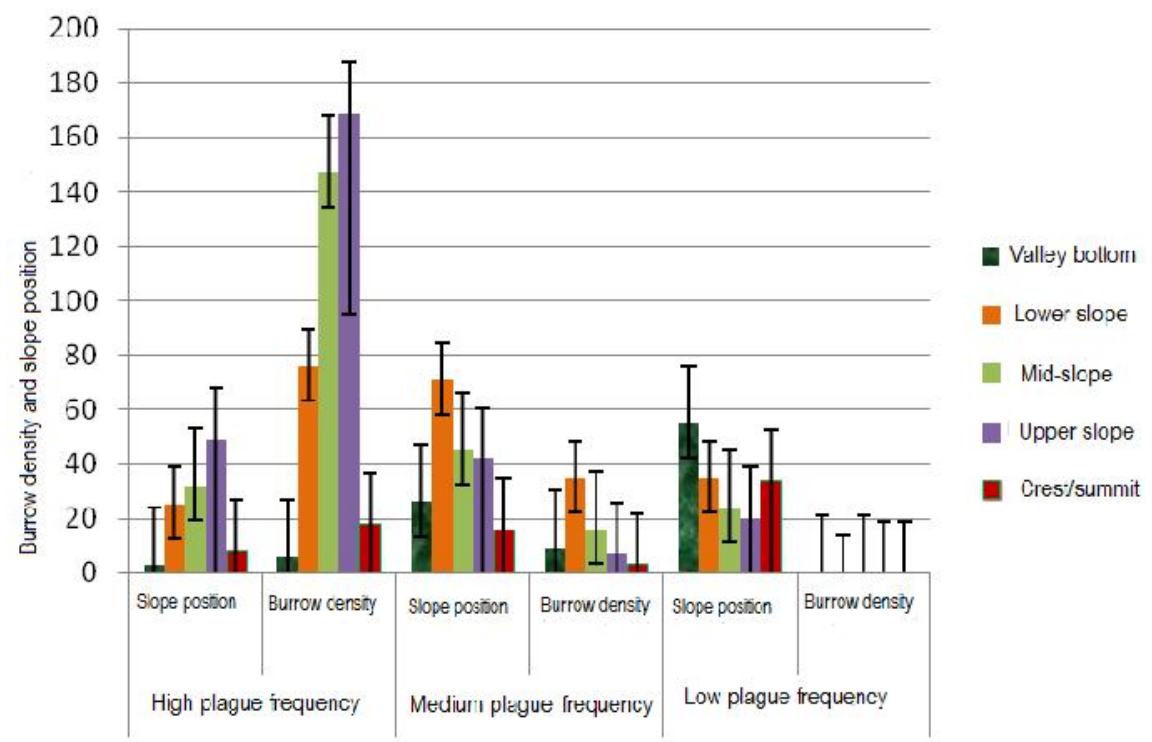

Figure 5: The influence of landform positions on rodent burrow distribution in the study area

\section{Distribution of rodent burrows as influenced by slope position}

Figure 5 presents the distribution of rodent burrows as influenced by slope position. It shows that there are differences within and between areas. In the high plague frequency landscapes (Lokome), upper slope positions had a significantly higher number of rodent burrows compared to other positions except for the mid-slopes. In the medium plague frequency area, burrow density was high on the mid-slope. There were no rodent burrows in the low plague frequency landscape (Figure 5).

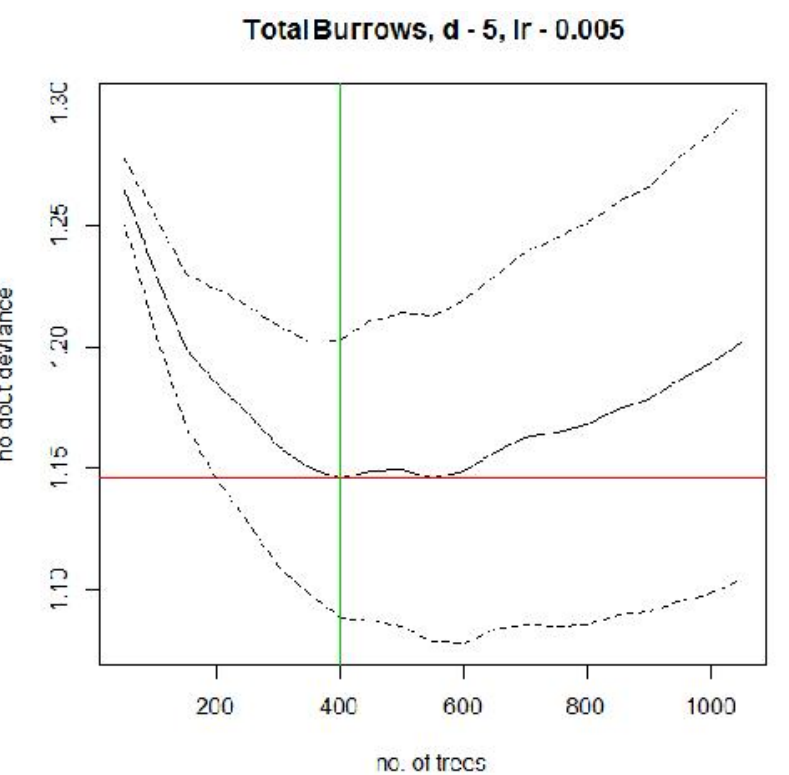

Figure 6: Model fit for landform and surface attributes for the high plague frequency area Fitting final gbm model with a fixed number of 400 trees for Total Burrows mean total deviance $=1.315$; mean residual deviance $=0.763$; estimated $\mathrm{cv}$ deviance $=1.146 ; \mathrm{se}=0.057$; training data correlation $=0.824 ; \mathrm{cv}$ correlation $=0.415 ;$ se $=0.075$; training data ROC score $=0.971 ; \mathrm{cv}$ ROC score $=0.728 ;$ se $=0.047$ 
Influence of landform and surface attributes on rodent burrows in the high plague frequency landscape

Figures 6 and 7, present results of the BRT model fit and partial plots of the rodent burrow predictors. In figure 7 the relative influence explaining the presence of rodent burrows is given in brackets. Model parameters show a good fit which implies that the identified predictors are representative. But it also suggests that the model does not explain every aspect that influences rodent burrows in the study area. Figure 7 presents the predictor variables explaining the presence of rodent burrows in the studied landscapes where out of 26 predictors only 8 with relative percent influence above 5.3 were picked by the model. Predicting variables are hillshade, slope gradient, herb cover, bare ground, elevation, longitudinal curvature (LongCurv), general curvature (GneralCurv) and plan curvature (PlanCurv) (Figure 6).
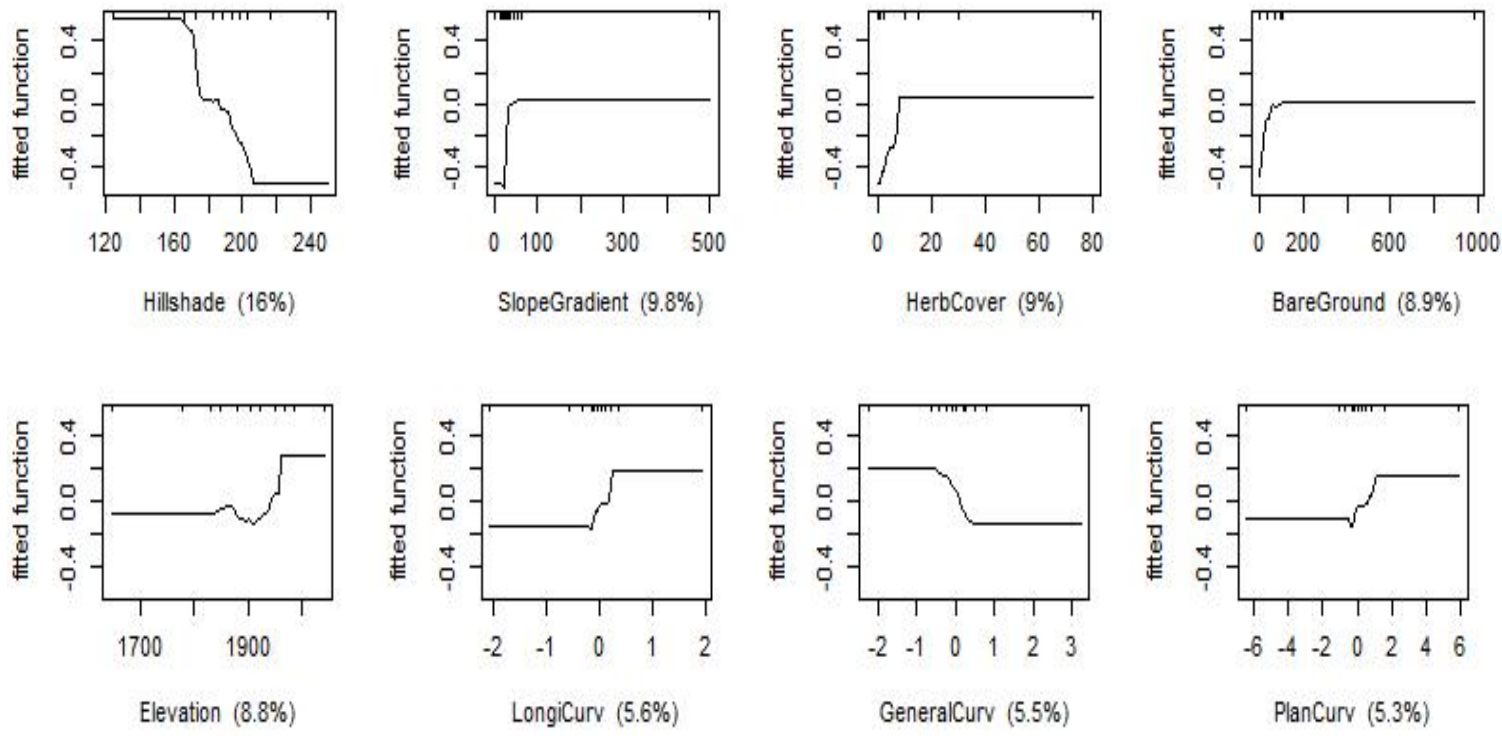

Figure 7: Partial dependence plots of the predictor variables explaining presence of rodent burrows in the studied landscapes

Interaction between predictors explaining the presence of rodent burrows in high plague frequency landscapes

Table 1 presents a summary of interactions of landform and surface attributes in explaining the presence of rodent burrows. Results show that 26 interacting attributes were contributing 9.13\% implying that $90.87 \%$ of the predicted rodent burrows were not accounted for by the present attributes. Results show that elevation and hillshade demonstrated a higher influence on the presence of rodent burrows followed by herb cover and general curvature, and herb cover and longitudinal curvature and hillshade (Table 1).

Table 1: Interaction between predictor variables explaining the presence of burrows in the high plague frequency landscapes

\begin{tabular}{llllll}
\hline No. & $\begin{array}{l}\text { Variable1 } \\
\text { index }\end{array}$ & $\begin{array}{l}\text { Variable1 } \\
\text { names }\end{array}$ & $\begin{array}{l}\text { Variable2 } \\
\text { index }\end{array}$ & $\begin{array}{l}\text { Variable2 } \\
\text { names }\end{array}$ & Interactions size \\
\hline 1 & 13 & Hillshade & 1 & Elevation & 4.31 \\
2 & 22 & HerbCover & 17 & GeneralCurv & 0.48 \\
3 & 22 & HerbCover & 18 & LongiCurv & 0.45 \\
4 & 18 & LongiCurv & 13 & Hillshade & 0.41 \\
\hline
\end{tabular}


Influence of landform and surface attributes to rodent burrows in the medium plague frequency landscapes

A model fit and partial plots for predictor variables that explain the presence of rodent burrows in the medium plague frequency landscape are presented in Figure 8 and 9. Whereas Figure 8 shows the limit at which the model develops partial plots to be 1900 trees, Figure 9 presents the eight predictors that were picked by the model out of 26 predictors tested. The relative influence of each predictor in the overall model is indicated in brackets of each partial plot.

TotalBurrows, $d=5$, Ir - 5e-04

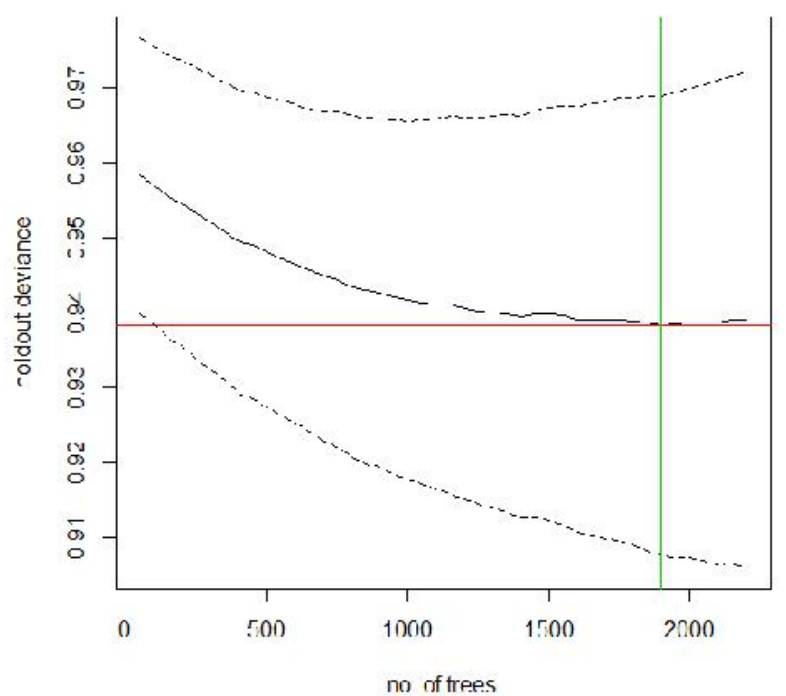

Figure 8: Model fit for landform and surface attributes in the medium plague frequency landscape

Fitting final gbm model with a fixed number of 1900 trees for Total Burrows: mean total deviance $=0.961$; mean residual deviance $=0.76$; estimated $\mathrm{cv}$ deviance $=0.938 ; \mathrm{se}=0.031$; training data correlation $=0.706 ; \mathrm{cv}$ correlation $=$ 0.168 ; se $=0.066$; training data $\mathrm{ROC}$ score $=0.957$; $\mathrm{cv}$ ROC score $=0.642$; se $=0.037$
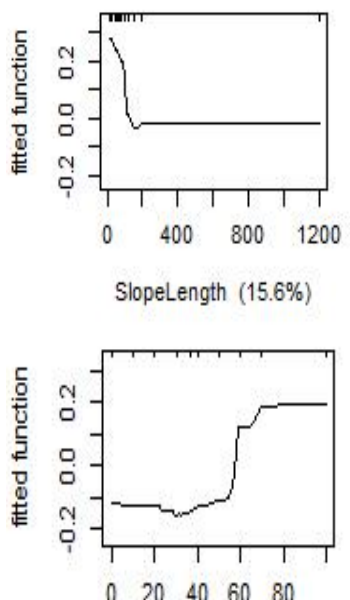

BareGround $(8.6 \%)$
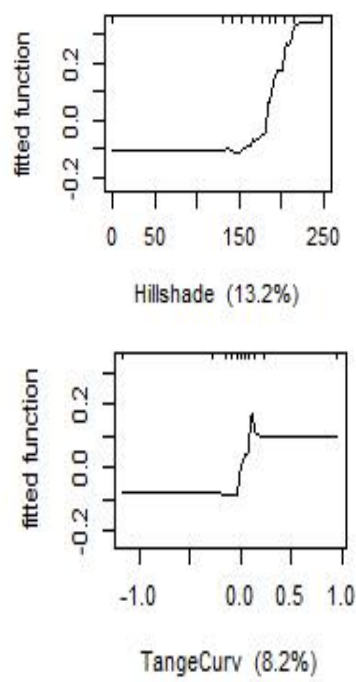
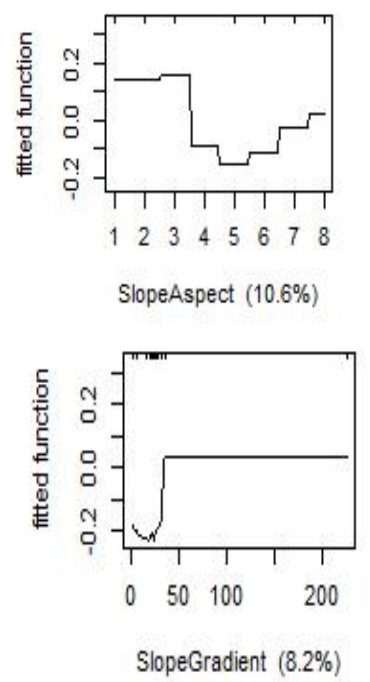
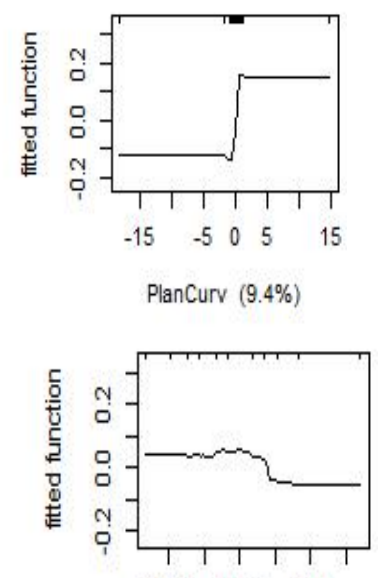

$17601800 \quad 1840$

Elevation (4.9\%)

Figure 9: Influence of landform and surface attributes on burrows in a medium plague frequency landscape 


\section{Interaction of attributes influencing rodent burrows in the medium plague frequency}

Table 2 presents a summary of interaction between attributes in explaining rodent burrow presence in the area. The attributes picked by the model are exactly the same as those observed in the high plague frequency landscape.

Table 2: Interaction between landform and surface attributes explaining the presence of rodent burrows in the medium plague frequency area

\begin{tabular}{llllll}
\hline No. & Variable1 index & Variable1 names & Variable2 index & Variable2 names & Interactions size \\
\hline 1 & 13 & Hillshade & 1 & Elevation & 4.31 \\
2 & 22 & HerbCover & 17 & GeneralCurv & 0.48 \\
3 & 22 & HerbCover & 18 & LongiCurv & 0.45 \\
4 & 18 & LongiCurv & 13 & Hillshade & 0.41 \\
\hline
\end{tabular}

\section{Discussion}

Slope gradient and slope aspect are landform characteristics observed in this study as determinants of ecological factors such as water flows, infiltration and erosive power of the surface run-off that have association with rodent habitats and burrowing. The slope aspect influences intensity of solar energy an area receives and the duration in hours by which the surface will be exposed to the solar radiation. It also influences and affects the amount of wind sweep on the local area, hence affecting local climate. Landform characteristics (slope gradient and aspect) have been documented to influence water movement on the land surface (Moore et al., 1991), surface processes and landforms (Lopes, 1997; Easterbrook, 1999; Furian et al., 1999; MacMillan \& Shary, 2009). On the other hand, the hydrological characteristics encourage resource availability such as water availability for vegetation growth which provides hiding places and food crops hence habitat to rodents (Busch et al., 2000). Therefore, the observed landform and slope differences and their influence on rodent burrows confirm the earlier findings which reported plague outbreaks associated with differences in landform characteristics in East Africa and those reported elsewhere (Witmer, 2004; Kamugisha et al., 2007; Stenseth et al., 2008).

The plague foci in East Africa have been associated with elevations well above 1,000m. For example Neerinckx et al. $(2008,2010)$ reported a positive correlation of high plague frequency at an elevation above 1,500m in West Usambara Mountains. Similar results have been reported by MacMillan et al. (2012) who indicated a high correlation between plague hosts and elevation above $1,300 \mathrm{~m}$ in a plague focus in Uganda. Also, elevation has been reported to influence plague host occurrence in Turkey (Yigit et al., 2003). Although, elevation alone could not be a factor for plague outbreaks, the reports suggest that high elevation areas have favourable conditions for habitats of the plague hosting rodents.

The high number of rodent burrows in a specific slope position could be attributed to multiple factors including habitat diversity. Various studies have indicated that rodents require safe habitats where they can live and reproduce (Busch et al., 2000; Davidson et al., 2008; Lambin et al., 2010; Piudo et al., 2011; Brabers, 2012; Lovy et al., 2013). In the upper slopes of the high plague frequency landscape (Lokome) there were dead tree stumps from harvested plantation forest. The upper part of the escarpment had many surface stones and rock outcrops. These features could provide safe shelter for rodents from predators. Also in these positions there was food crops intercropped with trees, on which rodents could live. The mid-slopes of Lokome were also characterised by cultivation and rock outcrops especially on the side which faces the escarpment which also provides safe shelter and abundant food.

The medium plague frequency landscape (Lukozi), showed a rather different scenario, where lower slopes had more rodent burrows although non-significantly different from other landform positions except for the ridge summits. In Lukozi, lower and middle slopes were the 
positions of high concentration for rodent burrowing. Both landform positions were characterised by Miraba (an indigenous land management practice with grass strips surrounding crop fields) which provide good cover for rodent burrowing. In addition, the lower slopes had continued food supply from nearby valley bottoms which are continuously cultivated and are within rodents' home range (Monadjem et al., 1998; Kilonzo et al., 2006)). However, there were only few burrows in the valley bottoms, possibly because the hiding places were limited due to continuous land tillage for vegetable farming. The results are similar to observations made earlier by Massawe et al. (2003) who indicated that methods of land preparation affect rodent distribution patterns and population abundance.

Predictors that influence rodent burrowing behaviour in the high plague frequency landscape show that 'hillshade', slope gradient, herbaceous cover, bare ground and curvatures were the strong determinants. The 'hillshade' which is a hypothetical illumination of surface to enhance topographic visualisation and graphical display (Susam, 2002), suggests that it may be playing a role of meeting energy demand in the habitat by length of time and intensity of time of the solar energy exposure in a given location. Some research findings elsewhere (Goyal \& Ghosh, 1993; Bogaart \& Troch, 2006; Busch et al., 2000) support the current results that hillshade encourages rodent burrowing due to its influence by intensity of sunshine on different landforms types. Other attributes of importance are slope gradient which probably influence land use through limiting accessibility within the habitats (Jaksic, 1986; Abramsky et al., 2000; Romanach, 2005; Nemati et al., 2013) and 'herbaceous cover' important for shelter and also forage provision (Eileen et al., 2000).

It has been reported that herbaceous cover provides protection particularly of diurnal and nocturnal raptors (eagles, owls) whose food source are rats (Taraborelli et al., 2009). Therefore, presence of herbaceous cover in certain parts of the study area was a good predictor of rodent burrow density (Jaksic, 1986; Hodara et al., 2000; Busch et al., 2000; Naderi et al., 2011). 'Bare ground' had comparatively high predictor in the model which suggests that animals avoid open places for risk avoidance (Nemati et al., 2013). High number of rodent burrows located under herbaceous cover around stone heaps, and under rock or boulders, is also in agreement with research findings by Yigit et al. (2003) in Turkey. Three types of curvature (planform, longitudinal and general) point out the relevance of convergence and divergence of water flow, important factors for rodent's selection of habitats (Rhodes \& Richmond, 1985; Kumar \& Pasahan, 1993). The results on interaction of factors influencing rodent burrowing behaviour in the studied landscapes as portrayed by the BRT models signify the importance of elevation, hillshade, curvature and herbaceous cover as determinants of rodent burrowing behaviour in both high and medium plague frequency landscapes.

The current study has demonstrated that the high plague frequency landscape has higher elevations, slope gradient and degree of dissection when compared to the medium and low plague frequency landscapes in the study area. In this study hillshade, slope gradient, herbaceous cover, bare ground, elevation, longitudinal curvature, general curvature and plan curvature are the important landform and surface attributes suggested to influence rodent burrows' abundance and distribution in the studied landscapes. The most predictor variables were high elevations, slope position and vegetation covers. Other surface attributes observed to pose a significant influence include dead tree stumps from harvested plantation forest, surface stones and rock outcrops where rodents could make rather safer burrows from predators especially raptors and domesticated animals. Also in these positions there was food crops intercropped with trees, which provided rodents with food on which they could live and multiply.

It is clear from this study that factors of landform and surface attributes investigated with respect to rodent burrowing could offer a better indication of rodent populations and hence good surrogates for prediction of plague risk areas. The current work compliments earlier researches most of which relating to rodents' survival and soil suitability for burrowing. 
The study has provided detailed quantitative and qualitative description of landforms and surface properties with respect to rodent burrows which could facilitate better ways of managing host and vector outbreaks and plague risks. However, there are pertinent questions which still remain that will require further investigations in future research on plague risks.

In the light of this study the following recommendations are pertinent: There are observed relations and differences between the three plague risk landscapes representing historical plague high, medium and low frequency respectively. However, the observed relations so far cannot explain the reported plague differences. Hence, integration of results from case studies with regard to landscape factors and other ecological studies using Ecological Niche Modelling (ENM) in the study area is strongly recommended. Ecohealth research approach to broaden the scope of plague research with work packages encompassing dormant reservoir of plague including wildlife reservoir, telluric reservoir, and vector-host communities as dependent on landforms, soils, surface attributes and human behaviour is strongly recommended.

\section{Acknowledgements}

This work was supported by a SUA-VLIR Own Initiative Project with Acronym LEPUS, financed by VLIR, Belgium and by the Ministry of Agriculture Food Security and Cooperative. The authors would like to acknowledge many people in Lushoto District who facilitated this work in different ways: Lushoto District Executive Director, District Agricultural and Livestock Development Officer, Sebastian Kolowa Memorial University, Tanzania, Lushoto District Subject Matter Specialists-Landuse and Health, village leaders, and farmers.

\section{References}

Abramsky, Z., Rosenzweigh, M.L. \& Subach, A. (2000) Measuring benefits of habitat selection. Behavioral Ecology 13, $497-502$.

Amatre, G., Babi, N., Enscore, R.E., Ogen-Odoi, A., Atiku, L.A., Akol, A., Gage, K.L. \& Eisen, R.J. (2009) Flea diversity and infestation prevalence on rodents in a plague-endemic region of Uganda. American Journal of Tropical Medicine and Hygiene 81, 718-724.

Annaert, B. (2010) Spatial Reconstruction of Land Cover Dynamics and Trajectories for the explanation of plague occurrence in the West Usambara Mountains, Tanzania. MSc Dissertation, Katholieke, Universiteit Leuven, Belgium, 99pp.

Bogaart, P.W. \& Troch, P.A. (2006) Curvature distribution within hill slopes and catchments and its effect on the hydrological response. Hydrology and Earth System Sciences Discussions 3 , 1071-1104.

Busch, C., Antinuchi, C.D., del Valle, J.C., Kittlein, M.J., Malizia, A.I., Vassallo, A.I. \& Zenuto, R.R. (2000) Population Ecology of Subterranean Rodents. In: (Edited by Eileen A. L., James, L. P. and Guy, N. C.), Life Underground: The Biology of Subterranean Rodents University of Chicago Press, Chicago. pp. $59-64$.

Brabers, L. (2012) Land characteristics, soil properties and microclimate associated with rodent burrows in a selected plague focus, Lushoto District, Tanzania. MSc Dissertation, Katholieke Universiteit Leuven, Belgium, 85pp.

Davidson, A.D., Lightfoot, D.C. \& McIntyre, J.L. (2008) Engineering rodents create key habitat for lizards. Journal of Arid Environments 72, 2142-2149.

Easterbrook, D.J. (1999) Surface Processes and Landforms. (2 ${ }^{\text {nd }}$ Ed.), Upper Saddle River. New Jersey Prentice Hall. 546pp.

Eileen, A.L., Patton, J.L. \& Cameron, G.N. (Eds.) (2000) Life Underground: The Biology of Subterranean Rodents. University of Chicago Press, Chicago. 449pp. 
Eisen, R.J., Borchert, J.N., Mpanga, J.T., Atiku, L.A., MacMillan, K., Boegler, K.A., Montenieri, J.A., Monaghan, A. \& Gage, K.L. (2012) Flea diversity as an element for persistence of plague bacteria in an East African plague focus. PLoS One 7 (4), 1-8.

Elith, J., Leathwick, J. R. \& Hastie, J. (2008) A working guide to boosted regression trees. Journal of Animal Ecology 77, 802-813.

FAO (2006) World Reference Base for Soil Resources 2006. A framework for International classification, correlation and communication. World Soil Resources Reports No.103. FAO, Rome, Italy. 145pp.

Furian, S., Barbiero, L. \& Boulet, R. (1999) Organization of the soil mantle in tropical southeastern Brazil (Serra do Mar) in relation to landslides processes. Catena 38, 65-83.

Goyal, S. P. \& Ghosh, P.K. (1993) Burrow structure of two gerbil species of Thar Desert, India. Acta Theriologica 38(4), $453-456$.

Hodara, K., Busch, M., Kittlein, M.J. \& Kravetz, F.D. (2000) Density dependent habitats selection between maize crop fields and their borders in two rodent species (Akodon azorae and Colomys laucha) of the Pampea agroecosystems. Evolutionary Ecology 14, 571-593.

Hubeau, M. (2010) Land use and human activity patterns in relation to the plague disease in the West Usambara Mountains, Tanzania. MSc Dissertation, Katholieke Universiteit, Leuven, Belgium, 97pp.

Jaksic, F.M. (1986) Predation upon small mammals in shrublands and grassland of southern South America: Ecological correlates and presumable Consequences. Revista Chilean de Historia Natural 59, $209-221$.

Kamugisha, M.L., Gesase, S., Minja, D., Mgema, S., Mlwilo, T.D., Mayala, B.K., Msingwa, S., Massaga, J.J. \& Lemnge, M.M. (2007) Pattern and spatial distribution of plague in Lushoto, North-Eastern Tanzania. Tanzania Health Research Bulletin 9,12-17.

Kilonzo, B.S., Mvena, Z.S.K., Machangu, R.S. \& Mbise, T.J. (1997) Preliminary observations on factors responsible for long persistence and continued outbreaks of plague in Lushoto district, Tanzania. Acta Tropica 68, 215-227.

Kilonzo, B.S., Mbise, T.J., Mwalimu, D.C. \& Kindamba, L. (2006) Observations on the endemicity of plague in Karatu and Ngorongoro, northern Tanzania. Tanzania Health Research Bulletin $8,1-6$.

Kumar, P. \& Pasahan, S.C. (1993) Effect of abiotic factors on the burrow density of some sympatric field murids. Journal of Biosciences 18, 149-153.

Lambin, E.F., Tran, A., Vanwambeke, S.O., Linard, C. \& Soti, V. (2010) Pathogenic landscapes: Interactions between land, people, disease vectors, and their animal hosts. International Journal of Health Geographics 9:54

Laundre, J.W. \& Reynolds, T.D. (1993) Effects of soil structure on burrow characteristics of five small mammal species. Great Basin Naturalist 53, 358-366.

Lopes, J.A.U. (1997) The Role of Landslides in the Landscape Evolution: Theoretical and practical aspects. Pan-American Symposium on Landslides, Rio de Janeiro, pp. 91- 100.

Lovy, M., Skliba, J. \& Sumbera, R. (2013) Spatial temporal activity patterns of the free living Giant Mole rate (Fukomys mechoniil). The Largest Social Bathyergid. PLoS One 8 (1).

MacMillan, K., Monaghan, A.J., Apangu, T., Griffith, K.S., Mead, P.S., Acayo, S., Acidri, R., Moore, S.M., Mpanga, J.T., Enscore, R.E., Gage, K. L. \& Eisen, R.J. (2012) Climate predictors of the spatial distribution of human plague cases in the West Nile Region of Uganda. American Journal of Tropical Medicine and Hygiene 86, 514-523.

MacMillan, K., Enscore, R.E., Ogen-Odoi, A., Borchert, J.N., Babi, N., Amatre, G., Atiku, L.A., Mead, P.S., Gage, K. L. \& Eisen, R.J. (2011) Landscape and residential variables associated with plague-endemic villages in the West Nile Region of Uganda. American Journal of Tropical Medicine and Hygiene 84, 435-442. 
MacMillan, R.A., \& Shary, P.A. (2009) Landforms and Landform Elements in Geomorphometry. In: (Edited by: T. Hengl \& H.I. Reuter) Geomorphometry concepts, software, applications. Developments in Soil. Elsevier, Amsterdam. pp. $227-254$.

Massawe, A.W., Leirs, H., Rwamugira, W.P. \& Makundi, R.H. (2003) Effect of Land Preparation Methods on Spatial Distribution of Rodents in Crop Fields. In: (Edited by G.R. Singleton, L.A. Hinds, C.J. Krebs \& D.M. Spratt) Rats, mice and people: Rodent biology and management. Australian Centre for International Agricultural Research, Canberra. pp. 229 - 232.

Mills, J.N., Gage, K.L. \& Khan, A.S. (2010) Potential influence of climate change on Vector-Borne and zoonotic diseases: A Review and proposed research plan. Environmental Health Perspective 118, 1507-1514.

Monadjem, A. \& Perrin, M.R. (1998) The effect of supplementary food on the home range of multimammate mouse Mastomys natalensis. South African Journal of Wildlife Research 28, 1-3.

Moore, I.D., Grayson, R.B. \& Landson, A.R. (1991) Digital terrain modelling: A Review of hydrological, geomorphological, and biological applications. Hydrological Processes 5, 3 30.

Mora, M.S., Mapelli, F.J., Gaggiotti, O.E., Kittlein, M.J. \& Lessa, E.P. (2010) Dispersal and population structure at different spatial scales in the subterranean rodent Ctenomys australis. BMC Genetics 11, 9.

Naderi, G., Hemami, M.R., Mohammadi, S., Riazi, B., Karami, M., Kaboli, M. \& Alesheikh, A.A. (2011) Effect of vegetation and soil conditions on burrow structure and site selection of rare desert rodent - Iranian jerboa (Allactaga Firouzi). Polish Journal of Ecology 59, 403411.

Neerinckx, S., Peterson, A.T., Gulinck, H., Deckers, J., Kimaro, D. \& Leirs, H. (2010) Predicting potential risk areas of human plague for the Western Usambara Mountains, Lushoto District, Tanzania. American Journal of Tropical Medicine and Hygiene 82, $492-500$.

Neerinckx, S.B., Peterson, A.T., Gulinck, H., Deckers, J. \& Leirs, H. (2008) Geographic distribution and ecological niche of plague in sub-Saharan Africa. International Journal of Health Geographics 7, $54-65$.

Nemati, F., Kolb, B. \& Metz, G.A. (2013) Stress and risk avoidance by exploring rats: Implication for stress management in fear related behaviours. Behavioral Processes 94, 89-98.

Piudo, L., Monteverde, M.J., Walker, R.S. \& Douglass, R.J. (2011) Rodent Community Structure and Andes Virus Infection in Sylvan and Peridomestic Habitats in Northwestern Patagonia, Argentina. Vector-Borne and Zoonotic Diseases 11, 315-324.

Ralaizafisoloarivony, N.A. (2010) Spatial Analysis of Vegetation and Small Mammals' Habitat for Prediction of Plague Reservoirs and Vectors in Mavumo area, Lushoto District, Tanzania. MSc Dissertation, Sokoine University of Agriculture, Morogoro, Tanzania, 154pp.

Randall, J.A. (1993) Behavioural adaptations of desert rodents (Heteromyidae). Animal Behaviour $45,263-267$.

Reichman, O.J. \& Smith, S.C. (1990) Burrows and Burrowing Behavior by Mammals. In: (Edited by Genoways, H.H.).Current Mammalogy. Plenum Press, London. pp. 197-244.

Ridgeway, G. (2007) Generalized boosted regression tree model. R package 'gbm'.[http://www.rproject.org/other-docs.html] site visited on 20/5/2012.

Rhodes, D.H. \& Richmond, M.E. (1985) The influence of soil moisture, texture, and temperature on Nest-site selection and burrowing activity by the Pine Vole, Microtus plnetorum. American Midland Naturalist 113, 102-108.

Romanach, S.S. (2005) Influences of sociality and habitat on African mole-rat burrowing patterns. Canadian Journal of Zoology 83, 1051-1058.

Stenseth, N.C., Atshabar, B.B., Begon, M., Belmain, S.R., Bertherat, E., Carniel, E., Gage, K.L., Leirs, H. \& Rahalison, L. (2008) Plague: Past, Present, and Future. PLoS Medicine 5 (1). 
Susam, T. (2002) The Different Use of Hillshade Image. An application in Tokat Province. International Symposium of GIS, Istanbul, Turkey, 4pp.

Taraborelli, P., Borruel, N., Sandobal, A. J. \& Giannoni, S. (2009) Influence of biotic and abiotic factors on the structure of burrows of the cavy Microcavia australis. Mastozoología Neotropical 16, $411-421$.

White, N.A., Engeman, R.M., Sugihara, R.T. \& Krupa, H.W. (2008) A comparison of plotless density estimators using Monte Carlo simulation on totally enumerated field data sets. BMC Ecology 8, 6.

Witmer, G.W. (2004) Rodent Ecology and Plague in North America. USDA National Wildlife Research Center, Fort Collins, Com., USA. 4pp.

Yigit, N., Colak, E., Sozen, M. \& Ozkurt, S. (2003) A study on the geographical distribution along with habitat aspects of rodent species in Turkey. Bonner Zoologische Beitrage 50, 355368. 